\title{
Transport of microplastics in coastal seas
}

\author{
Hua Zhang \\ Key Laboratory of Coastal Zone Environmental Processes and Ecological Remediation, Yantai Institute of Coastal Zone Research, Chinese Academy of \\ Sciences, Yantai 264003, China
}

\section{A R T I C L E I N F O}

\section{Article history:}

Received 11 July 2017

Received in revised form

21 September 2017

Accepted 29 September 2017

Available online 30 September 2017

\section{Keywords:}

Marine plastic debris

Coastal transport

Marine sediments

Particle transport

Turbulent mixing

Hydrodynamics

\begin{abstract}
A B S T R A C T
Microplastic pollution of the marine environment has received increasing attention from scientists, the public, and policy makers over the last few years. Marine microplastics predominantly originate near the coast and can remain in the nearshore zone for some time. However, at present, there is little understanding of the fate and transport of microplastics in coastal regions. This paper provides a comprehensive overview of the physical processes involved in the movement of microplastics from estuaries to the continental shelf. The trajectory and speed of microplastics are controlled by their physical characteristics (density, size, and shape) and ocean dynamic conditions (wind, waves, tides, thermohaline gradients, and the influence of benthic sediments). Microplastic particles can be subjected to beaching, surface drifting, vertical mixing, and biofouling, as well as bed-load and suspended load transport processes, until reaching terminal deposition on beaches, in coastal marshes, in benthic sediments or until they are carried by ocean currents to subtropical convergence zones. The dynamic interaction of released microplastics with the shoreline is regulated by onshore/offshore transport, which is impacted by the source location as well as the geometry, vegetation, tidal regime, and wave direction. Wind and wave conditions dominate surface drifting of buoyant particles through Ekman drift, windage, and Stokes drift mechanisms. Neustic microplastic particles travel in the subsurface because of vertical mixing through wind-driven Langmuir circulation and heat cycling. Increasing accumulation of microplastics in benthic sediments needs to be quantitatively explored in terms of biofouling, deposition, entrainment, and transport dynamics. Further studies are required to understand the following: 1) the primary parameters (e.g., windage, terminal velocity, diffusivity, critical shear stress) that determine microplastic transport in different pathways; 2) dynamic distribution of microplastics in various coastal landscapes (e.g., wetlands, beaches, estuaries, lagoons, barrier islands, depocenters) regulated by hydrodynamic conditions; and 3) interactions between the physical transport processes and biochemical reactions (degradation, flocculation, biofouling, ingestions).
\end{abstract}

(c) 2017 Elsevier Ltd. All rights reserved.

\section{Contents}

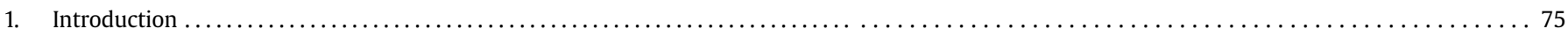

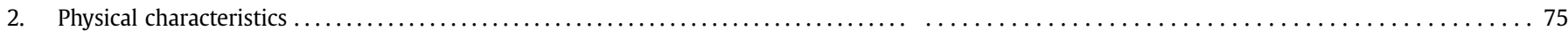

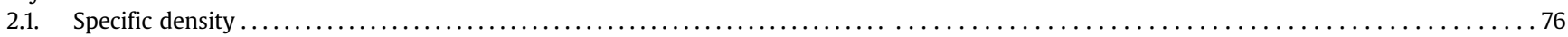

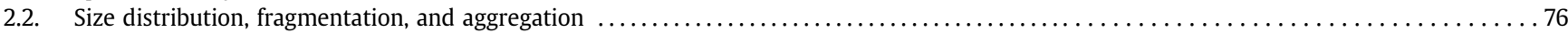

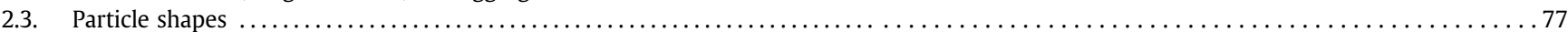

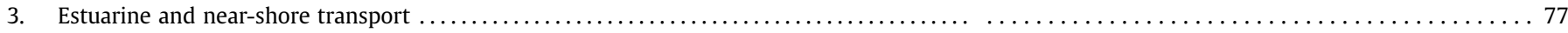

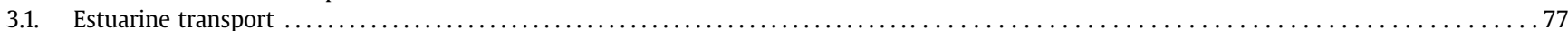

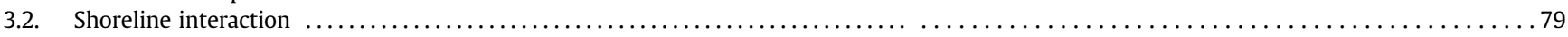

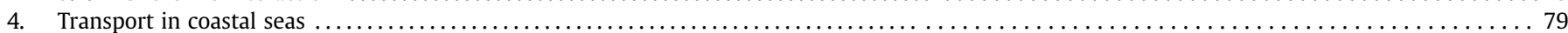

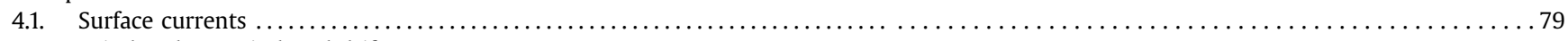

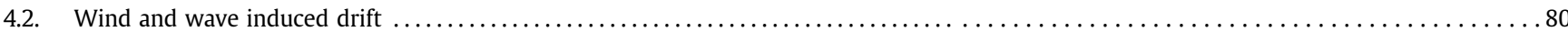

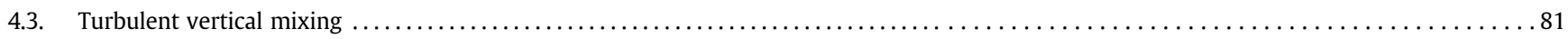

E-mail address: hzhang@yic.ac.cn. 


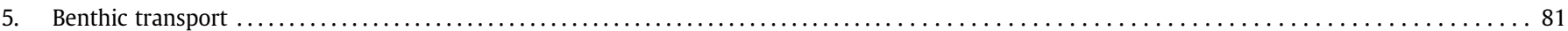

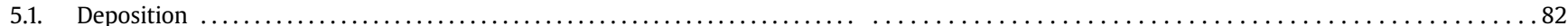

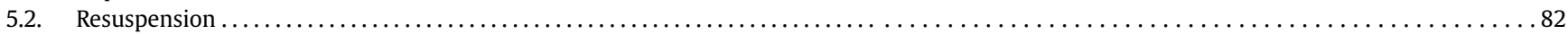

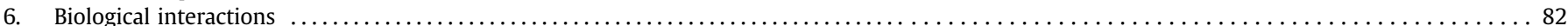

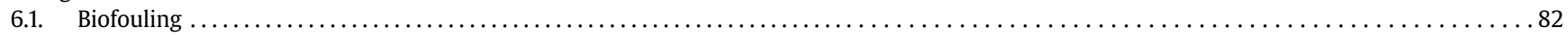

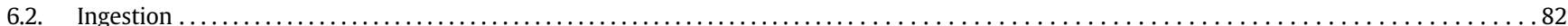

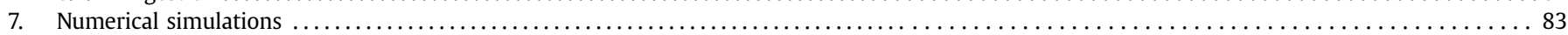

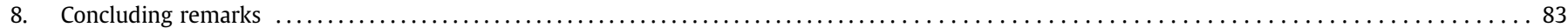

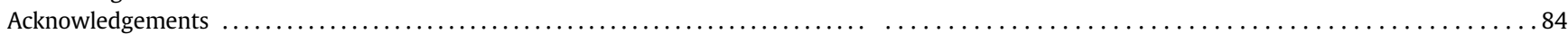

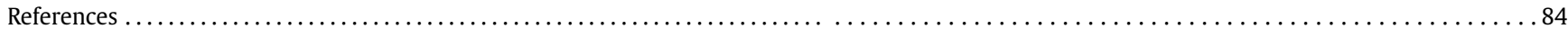

\section{Introduction}

Since the start of the plastic industry in the 1940s, worldwide production and use of plastic has increased exponentially, reaching 322 million tons of production per year in 2015 (PlasticsEurope, 2016). Although wide application of plastic material has brought far-reaching societal benefits, improper management of plastic waste has caused increasing negative impacts on the environment, especially on marine ecosystems. It has been estimated that 4.8 to 12.7 million tons of plastic waste entered the ocean in 2010, and the number is predicted to increase by an order of magnitude by 2025 (Jambeck et al., 2015).

Recent environmental concern has focused on microplastics (millimeters or smaller), which are the most abundant and potentially harmful fraction of plastic debris in the ocean (Law and Thompson, 2014). Microplastics include primary microplastics used as scrubbers in cosmetic products and air-blasting media as well as secondary microplastics derived from the fragmentation of large plastic debris (Cole et al., 2011; Filella, 2015). Microplastics pollution has been documented throughout the world and has become the focus of the scientific community, governments and intergovernmental agencies, as well as the public (Andrady, 2011). The ubiquitous presence of microplastics in almost every type of marine habitats has been reported, from the surface and subsurface water columns (Cózar et al., 2014), to beach and wetland sediments (Hidalgo-Ruz et al., 2012), and even the polar region (Eriksson et al., 2013; Lusher et al., 2015; Waller et al., 2017) and deep sea (van Cauwenberghe et al., 2013; Woodall et al., 2014). Marine pollution from microplastics has been recognized as a worldwide environmental and ecological threat (GESAMP, 2015). The environmental impacts of microplastics include ingestion hazards to marine mammals, fish, seabirds, and planktonic organisms (Wright et al., 2013; Galloway et al., 2017), the provision of substrate for undesirable microorganisms (Carpenter et al., 1972; Barnes et al., 2009), and its' role as a carrier of toxic chemicals (Bakir et al., 2014; Koelmans et al., 2015; Wang et al., 2016).

Approximately half of the world's population lives near the coast, which makes the coastal zone a hot spot for microplastic contamination (Cole et al., 2011). Direct sources of plastics near shore include land-based sources (e.g., beach littering, sewage treatment plants, urban and agricultural runoff), maritime activities (marine aquaculture, shipping, oil drilling), river discharge, and potentially atmospheric dust (GESAMP, 2015; Thompson, 2015; Li et al., 2016; Auta et al., 2017). Studies have demonstrated that there is strong correlation between nearshore plastic concentrations and coastal populations (e.g., Barnes et al., 2009; Browne et al., 2011; Yonkos et al., 2014; Zhao et al., 2015; Pedrotti et al., 2016). The highest concentrations of microplastic particles have been observed in coastal and harbor areas as well as near industrial sites (e.g., Claessens et al., 2011; Desforges et al., 2014; Auta et al., 2017). Numerous field survey and modeling studies have shown that most of the plastics released into the marine environment stay near the coastline after many years or even decades (e.g., Lebreton et al., 2012). Beach sediment is an obvious accumulation zone for plastic debris (e.g., Liebezeit and Dubaish, 2012; Dekiff et al., 2014; Mathalon and Hill, 2014; Yu et al., 2016). High concentrations of microplastics have been observed in subtidal and marine sediments around the world (Ng and Obbard, 2006; Thompson et al., 2004; Claessens et al., 2011). Recent studies have demonstrated that intertidal flats, including mangrove habitats (Nor and Obbard, 2014) and salt marsh habitats (Weinstein et al., 2016), are important sinks for microplastics (Fig. 1).

Substantial research efforts have been dedicated to studying the interactions of microplastics with chemical pollutants, microbes, planktons, as wells as vertebrate and invertebrate animals in marine environments (do Sul and Costa, 2014). In comparison, only a few studies have been carried out to characterize the physical transport of microplastics (Critchell and Lambrechts, 2016; Vermeiren et al., 2016). Understanding the transport processes can be challenging, since the physical characteristics (e.g., density, size, shape, buoyancy) of microplastics vary on a wide range. Thus, different classes of microplastics may have varying sources/sinks, trajectories, travel distances, and residence times. In the last decade, physical mechanisms regulating the accumulation of plastic debris in subtropical convergence zones have been successfully elucidated with a combination of field surveys, global drifter arrays, and numerical modeling (Barnes et al., 2009; Law et al., 2010; Howell et al., 2012; Cózar et al., 2014). However, a large knowledge gap exists about the physical processes involved in the fate and transport of plastic particles in coastal seas. Studies have not been conducted to collectively examine the relative importance of hydrodynamic forces (i.e., wind, wave, tide, salinity), the depositional environment (shoreline, coast geomorphology, benthic sediment), or the density and size of microplastics (Browne et al., 2010).

This article critically reviews recent field observations and numerical modeling efforts about the physical transport of microplastic in estuaries and coastal regions. Our discussion also relies on the extensive literature available on the transport of other marine particles (e.g., sediments, plankton, organic matter, oil spills) that share similar physical prospects. The objectives are to identify current understanding, information gaps and research priorities.

\section{Physical characteristics}

Thousands of polymers have been synthesized over a wide range of density and texture. Upon entering the natural environment, their physical properties are further modified through mechanical breakdown, photochemical degradation, biofouling, and coagulation. Therefore, microplastic samples collected from water and sediments vary in their particle density, size distribution (nano-, micro-, and millimeters), geometric shape (e.g., fiber, 


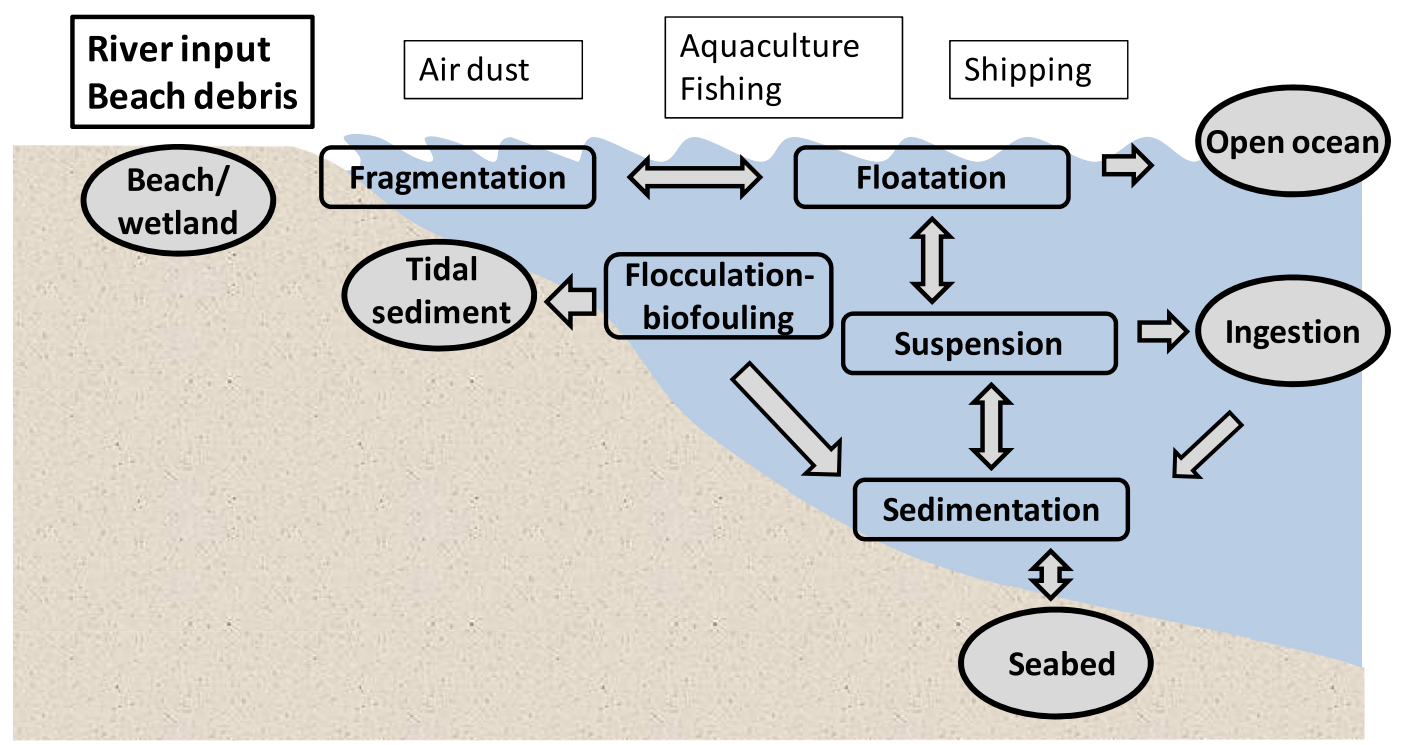

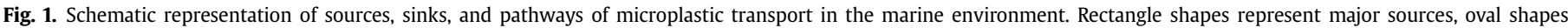
represent major sinks, rounded rectangles represent major transport pathways, and black arrows show the fluxes between the different compartments.

sheets, spherical, ovoid, cylindrical), and surface characteristics. The buoyancy of particles is a function of their physical properties (Table 1), and largely determines their eventual fate (Filella, 2015; Ryan, 2015).

\subsection{Specific density}

The particle densities of plastics vary considerably, depending upon the polymer types and manufacturing processes. Virgin resins of plastics have material densities $\left(\rho_{p}\right)$ ranging from 0.8 to $1.4 \mathrm{~g} \mathrm{~cm}^{-3}$. With a density close to sea water $\left(\rho_{w}\right)$, the most commonly-found plastics in marine environments are polyethylene (PE: 0.90-0.99 $\mathrm{g} \mathrm{cm}^{-3}$ ), polypropylene (PP: $0.85-0.95 \mathrm{~g} \mathrm{~cm}^{-3}$ ), and polystyrene (PS: $0.95-1.1 \mathrm{~g} \mathrm{~cm}^{-3}$ ). Styrofoam has extremely low density of $0.045 \mathrm{~g} \mathrm{~cm}^{-3}$ and is widely observed on the sea surface and along shorelines. High-density microplastics, including polyvinylchloride (PVC: $1.1-1.58 \mathrm{~g} \mathrm{~cm}^{-3}$ ), polyamide (PA: $1.02-1.15 \mathrm{~g} \mathrm{~cm}^{-3}$ ), and polyethylene terephthalate (PET: $1.38-1.45 \mathrm{~g} \mathrm{~cm}^{-3}$ ) are likely found in the benthic environment (Morét -Ferguson et al., 2010; Andrady, 2011; Hidalgo-Ruz et al., 2012). Because of degradation and flocculation processes, the density of plastic particles might change with residence time in the marine environment. Growth of the fouling community, including microorganisms and plankton on the surfaces of plastics, can contribute to changes in particle density. For instance, (Morét

Table 1

Transport pathways of plastics as a function of their density and size.

\begin{tabular}{lll}
\hline Size/density & Low density $^{\mathrm{a}}$ & High density \\
\hline Macroplastic $^{\mathrm{b}}$ & Floatation & Sedimentation \\
Mesoplastic & Floatation & Suspension \\
& Suspension & Sedimentation \\
Microplastic & Floatation & Suspension \\
& Suspension & Aggregation-sedimentation \\
& Aggregation-sedimentation & \\
Nanoplastic & Suspension & Suspension \\
& Aggregation-sedimentation & Aggregation-sedimentation \\
\hline
\end{tabular}

\footnotetext{
${ }^{a}$ Low density: specific density < sea water density; High density: specific density $>$ sea water density.

b Macroplastic: >200 mm; mesoplastic: 5-200 mm; microplastic: $0.1 \mu \mathrm{m}-5 \mathrm{~mm}$;
} nanoplastic: $<0.1 \mu \mathrm{m}$.
-Ferguson et al., 2010) reported that the densities of pelagic plastic differed considerably from that of beach plastics, reflecting the transformation they underwent during migration at sea.

Particle density $\left(\rho_{p}\right)$ is a critical parameter determining the buoyancy and mobility of microplastics in water. In general, nonfloating particles with densities higher than sea water tend to settle down to the sea bottom, while neustic particles with densities lower than seawater float at or near the sea surface (Barnes et al., 2009; Kowalski et al., 2016; Chubarenko et al., 2016). However, the trajectory of microplastics in the marine environment can be rather complex due to hydrodynamic mixing processes (Browne et al., 2010; Collignon et al., 2012; Ballent et al., 2012, 2013) and the coagulation of particles (Long et al., 2015). As a result, high-density particles might travel long distances and low-density particles have been found in benthic sediments in coastal seas (e.g., Hidalgo-Ruz et al., 2012; Thompson, 2015; Frère et al., 2017) and on the deep ocean floor (van Cauwenberghe et al., 2013; 2015; Shimanaga and Yanagi, 2016). Given the material density of plastics and the turbulent conditions of coastal seas, it is expected that transport as a suspended load might be a major pathway for non-buoyant plastic particles.

\subsection{Size distribution, fragmentation, and aggregation}

Although debate remains over the exact size limits, marine plastics are categorized as macroplastic $(>200 \mathrm{~mm})$, mesoplastic (5-200 mm), and microplastic ( $<5 \mathrm{~mm}$ ) (Costa et al., 2011; Cole et al., 2011; Andrady, 2011; Lee et al., 2013). In practice, the minimum sizes $(d)$ of microplastics vary from 0.5 to $2 \mathrm{~mm}$ for sieved samples, $0.053-3 \mathrm{~mm}$ for neuston nets, and $1.6-2 \mu \mathrm{m}$ for filtered samples (Hidalgo-Ruz et al., 2012). The size range of microplastics is similar to that of silt and sand, micro-, meso-, and macrofauna benthos species, as well as micro- and macroplankton. Furthermore, microplastics might further fragment into nano-plastics $(<0.1 \mu \mathrm{m})$ in the marine environment, and nano-plastics are likely to be of increasing significance because of their direct impact on the marine food web (Andrady, 2011; Cole et al., 2011; Koelmans et al., 2015; Besseling et al., 2017).

Size specific sedimentation has been proposed to explain the distribution pattern of microplastic in the world's oceans (Cózar 
et al., 2014; Ryan, 2015; Fazey and Ryan, 2016a). Large plastic debris with density less than sea water floats at high velocity over rather long distances by surface current and wind forces, whereas large non-buoyant plastics dominantly deposit on near shore sediments (Table 1). Regardless of their densities, tiny plastic pieces exhibit behavior of colloidal particles and mainly exist as suspended particles in the water column (Filella, 2015). Furthermore, a series of reactions, including fragmentation, flocculation, biofouling, and aggregation can modify the size distribution of plastic particles, which need to be treated as a dynamic parameter depending on residence time and traveling pathways (Ryan, 2015; Auta et al., 2017).

The fragmentation of plastic debris into gradually smaller pieces is caused by a combination of mechanical breakdown, photodegradation, and possibly microbial degradation. In coastal environments, the physical forces of wind, waves, and tides cause the abrasion of plastics on the sea surface and beach sediments (Browne et al., 2010; Barnes et al., 2009; Lee et al., 2013; Fok et al., 2017). Photodegradation of the polymer matrix leads to bond cleavage and makes plastics brittle, causing them to disintegrate (Andrady, 2011; Barnes et al., 2009; Moore et al., 2002; ter Halle et al., 2016). The heat and sunlight, and the well-aerated conditions near the coast are ideal for generating micro- and nanoplastics through iterative fragmentation processes. However, in cold, anoxic conditions of marine waters and sediments, it could take centuries for plastic particles to fragment (Harshvardhan and Jha, 2013).

Aggregation with organic and inorganic particles can increase the size and density of microplastics and cause rapid deposition onto benthic sediments. Given the high concentrations of suspended sediments, particulate organic matter, and detrital particles in the coastal environment, aggregation and subsequent sedimentation might dominate the fate and distribution of microplastics. However, a lack of research makes it difficult to evaluate the settling rate of plastic aggregates (Filella, 2015). A modeling study by Besseling et al. (2017) demonstrated that the excess mass of suspended kaolin or bentonite clay particles that form heteroaggregates with microplastic overwhelmed the particle density variation and biofilm formation as a major process controlling the fate and retention of microplastics.

\subsection{Particle shapes}

Marine plastic particles exist in various shapes depending on their original type (plastic fragments, pellets, fibers, filaments, plastic films, foamed plastic, granules, and styrofoam) and fragmentation processes (Hidalgo-Ruz et al., 2012). Granular particles (irregular fragments, pellets) are common shapes of plastics on the sea surface and beaches (Browne et al., 2010). Thin plastic films degraded from garbage and grocery bags as well as from greenhouse and construction films were a common type of plastic observed in coastal systems that might further break up into threads and filaments due to mechanical abrasion and photodegradation. Fibers of different origins (washing clothes, ropes and fishing gear, and fiber-reinforced ships) are a ubiquitous form of microplastic found in the water column and sediment (Browne et al., 2011; Woodall et al., 2014; Sutton et al., 2016). Furthermore, the formation of cracks, fractures, scratches, pits, and grooves through fragmentation processes are commonly observed surface features of microplastics.

Highly irregular shapes among microplastic particles indicates that their hydrodynamic characteristics might substantially deviate from classical theories developed based on the assumption of spherical particles (Chubarenko and Stepanova, 2017). For instance, fibers and thin films may have higher buoyancy and lower settling velocity than spheres with the same density and volume (Filella, 2015). Therefore, equivalent spherical diameters (ESD) need to be calculated as a measure of irregular particles and incorporated into mathematical formulas used to estimate the windage and settling velocity (Kowalski et al., 2016; Khatmullina and Isachenko, 2017). Furthermore, particle shape and specific surface area are important parameters for determining the aggregation and biofouling processes, which thereby impact the transport pathway of microplastics (Chubarenko et al., 2016). Particles with high surface area to volume ratios (films, fibers, foams) have a higher rate of aggregation/biofouling and may sink sooner than large items (Ryan, 2015).

\section{Estuarine and near-shore transport}

Coastal seas are an energetic region with continuous influence from strong hydrodynamic factors, including tides, wind, waves, and thermohaline gradients. Consequently, the temporal and spatial distribution of microplastic indicates that dynamic patterns are shaped by climatic forces and coastal transport processes (Yoon et al., 2010; Ballent et al., 2013; Isobe et al., 2014; Liubartseva et al., 2016; Critchell et al., 2015; Critchell and Lambrechts, 2016; Vermeiren et al., 2016). Inputs of plastics from land, riverine, and marine sources go through beaching, drifting, and settling pathways until they reach temporary reservoirs on beaches, tidal wetlands, and marine sediments. A fraction of the plastics entering coastal areas are carried by offshore currents on their journey to the open ocean. The trajectory and velocity of microplastics are controlled by hydrodynamic processes, such as longshore and cross-shore transport, tidal pumps, estuarine circulation, Stokes drift, and bed-load transport (Fig. 2).

\subsection{Estuarine transport}

Estuarine hydrodynamics have profound implications for microplastic inputs into the marine environment. The distribution of microplastics in river mouths is influenced by the large temporal variations in river discharge and particle flux (Moore et al., 2002; 2011; Yonkos et al., 2014; Cheung et al., 2016). On reaching an estuary, hydrodynamic forces (wave and tide induced turbulence, as well as freshwater induced stratification and plume fronts) act on microplastic particles to follow advection, dispersion, suspension, and settling pathways (Sadri and Thompson, 2014; Lima et al., 2015; Eerkes-Medrano et al., 2015; Vermeiren et al., 2016; Krelling et al., 2017). High suspended inorganic and organic particle content in river discharge might interact with particle density, size, and charge, leading to increased aggregation and deposition (Besseling et al., 2017). It has been suggested that microplastic transport in rivers and estuaries may be like well-studied sediment transport (Galgani et al., 2000; Browne et al., 2010; Costa et al., 2011; Ballent et al., 2012; Eerkes-Medrano et al., 2015).

Plastic wastes from production and consumption on upstream land are ultimately transported by surface runoff through watersheds into river systems (Moore et al., 2011; Lechner et al., 2014; Sadri and Thompson, 2014; Fok and Cheung, 2015; EerkesMedrano et al., 2015; Besseling et al., 2017). Due to the lack of monitoring data, it is still unclear how much riverine flux contributes to microplastics pollution. However, it is certain that rivers are important pathways for plastics migration from terrestrial sources into the marine environment. Using water samples from two Los Angeles rivers collected from 2004 to 2005, Moore et al. (2011) revealed that over 2 billion plastic particles were released from the rivers into the marine environment over a 3-day period. It is estimated that 1533 tons per year of microplastic enter the Black sea from the Danube (Lechner et al., 2014). Part of the microplastic entering the river mouth can be efficiently retained in riparian and 


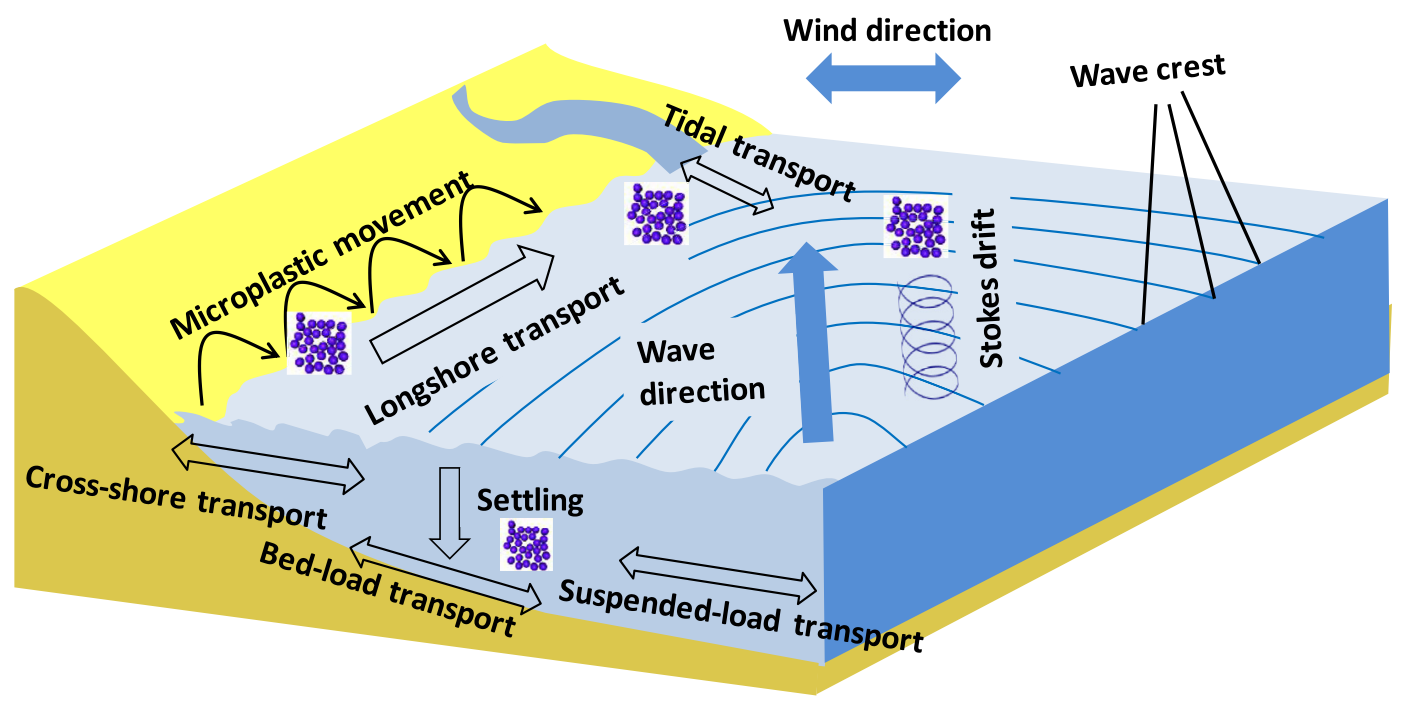

Fig. 2. Schematic diagram of near-shore microplastic transport mechanisms (modified from Critchell and Lambrechts, 2016)

hyporheic zones, thereby reducing the discharge into coastal seas and oceans (Eerkes-Medrano et al., 2015; Besseling et al., 2017; Krelling et al., 2017). A survey of the Tamar River Estuary, in the UK, in late spring and summer suggested that rivers were neither a source nor a sink, with near equal amounts of microplastic particles entering the estuary as leaving it (Sadri and Thompson, 2014). Transport modeling indicated that part of the nano- and microplastic can be retained in river systems through deposition following aggregation and/or biofilm growth (Besseling et al., 2017).

Stormwater events might dominate the export of terrestrial microplastic. The highest amount of microplastics in river mouths has commonly been observed during the rainy season when floodwater discharges from upstream (Lattin et al., 2004; Moore et al., 2002, 2011; Yonkos et al., 2014; Lima et al., 2015; Cheung et al., 2016; Veerasingam et al., 2016). For example, surface microplastic debris in Californian waters increased 6-fold and deposited at greater distances from the river mouth following a storm (Lattin et al., 2004). The accumulation of debris at the mouth of two small rivers on Hawaii was significantly correlated with precipitation events, and the first rainfall event after a dry period may discharge a disproportionate amount of debris (Carson et al., 2013). Wind direction and speed could affect the transport of buoyant plastics where shores downwind accumulate higher amounts of plastic debris (Browne et al., 2010; Sadri and Thompson, 2014). Furthermore, strong winds and associated wave action may cause vertical mixing within the water column and resuspend plastics from the bottom (Kukulka et al., 2012; Reisser et al., 2015). Consequently, it has often been observed that microplastic concentrations on the open sea surface are lower under windy conditions. In the Tamar Estuary, UK, downwind sites were generally found to contain $>3$ times more microplastics than upwind sites (Browne et al., 2010). A study in the Chesapeake Bay watershed detected peaks in microplastics concentrations after Hurricane Irene and Tropical Storm Lee, which were likely attributable to increased runoff from terrestrial debris as well as resuspension of plastics already in the water column and sediment (Yonkos et al., 2014). However, the exact role of wind on microplastics transport in estuaries remains unclear (Zhao et al., 2015).

Strong tidal currents occurring in many estuaries could considerably influence the residence time and transport of microplastics. Flood-ebb and spring-neap variations of circulation, mixing, and stratification can affect the net transport of microplastics in estuaries. The exact direction and flux of tidal transport need to be resolved in terms of the tidal regime and geometry of specific estuaries (Wolanski and Elliott, 2015). An observation of the macrotidal Tamar Estuary, UK, indicated that particle size distribution was significantly different between the spring and neap tides, with a shift towards smaller size classes and lower abundance during the neap/ebb tide (Sadri and Thompson, 2014). Modeling results indicated that non-buoyant plastic pellets might be transported up and down Nazaré Canyon (Portugal) as a function of tidal forces, with only minor net down canyon movement (Ballent et al., 2013). In energetic estuarine systems, tidal energy dissipation in shallow water generates an ebb-flood asymmetry in the vertical profile of longitudinal velocity (Becherer et al., 2016) and yields a residual flow that may carry the microplastics seaward or landward.

Stratification and mixing at the interface of riverine freshwater and saline seawater are important factors affecting the movement of buoyant and non-buoyant plastic debris. Differences between the specific gravity of freshwater $\left(1.00 \mathrm{~g} \mathrm{~cm}^{-3}\right)$ and seawater (1.03 $\mathrm{g} \mathrm{cm}^{-3}$ ) might affect the buoyancy of plastics with particle densities falling near the range. The horizontal and vertical gradient of specific gravity might be a controlling factor determining the distribution of certain types of plastics in the water column (Lima et al., 2015; Vermeiren et al., 2016). Estuarine plume fronts generally have low circulation and high sedimentation rates, which favor the accumulation of floating and settling plastics. Acha et al. (2003) observed that high concentrations of debris coincided with a bottom salinity front at the mouth of the Rio de la Plata, which indicates that estuarine fronts act as a barrier for drifting debris and accumulates them on the sea floor. Front formation in the water column in the middle portion of the Goiana Estuary during stable hydrological conditions during the dry season were suggested to be the mechanism prohibiting movement of microplastics from the upper to lower estuary (Lima et al., 2015). The maximum turbidity zone is well known as an accumulation zone for various pollutants transported with suspended particles (e.g., Herman and Heip, 1999) and might as well be an important sink for plastic wastes. Outside the plume front, estuarine circulation driven by a horizontal density gradient results in residual currents directed seaward at the surface and landward at the bottom (Becherer et al., 2016), which favors the offshore transport of floating plastics and the settling of non-buoyant plastics. 


\subsection{Shoreline interaction}

The shoreline might be the main sink for plastics in coastal seas (Thornton and Jackson, 1998; Thiel et al., 2013). The presence and accumulation of plastic debris on the surface and in sediments along beaches are obvious and frequently reported throughout the world because of the aesthetic damage (e.g., $\mathrm{Ng}$ and Obbard, 2006; Costa et al., 2011; Claessens et al., 2011; Zhou et al., 2011; Heo et al., 2013; Stolte et al., 2015; Fok et al., 2017). However, the mechanisms and controlling factors of dynamic onshore and offshore microplastic transport remain unclear and require well-designed field experiments and numerical models (Critchell et al., 2015; Moreira et al., 2016).

Floating plastics may be cast onto rocky shores or sandy beaches with surface currents and onshore wind/wave. Stranded plastic particles are easily washed back into sea during spring tides or storms. The repetitive onshore-offshore transport of plastics persists until they are free from the near-shore trapping and are carried to the open sea with cross-shore transport (Thiel and Gutow, 2005; Fok et al., 2017). The shoreline interaction of microplastics also depends on shoreline characteristics, such as the substrate structure (bedrock/gravel/sand/mud), vegetation, bioturbation, and surface ice. Modeling the shoreline interaction of plastic debris is often based on a simplified assumption of permanent retention after stagnation on the shoreline for a certain amount of time (Yoon et al., 2010; Mansui et al., 2015; Liubartseva et al., 2016).

On wind- and wave-dominated shorelines, the height at which plastics become stranded depends on wave action and the size/ weight of particles (Carson et al., 2013). The cross-shore distribution of plastics often exhibits small low-density debris on the upper profile that is dominated by wind and heavier debris on the lower profile that is dominated by waves (Thornton and Jackson, 1998; Thiel et al., 2013). Furthermore, turbulent mixing with beach sediments may accelerate the fragmentation of plastic particles, bury them inside the sediment, and protect them from washing back into the sea water. Turra et al. (2014) demonstrated that microplastics can be found in the vertical profile of beach sediment as deep as $2.0 \mathrm{~m}$ and suggested that high-energy oceanographic events, such as sea storms, are the mechanism for microplastic burial.

The distribution of plastics in the intertidal zones exhibits dynamic spatial-temporal patterns according to the local geometry and tidal regimes (McDermid and McMullen, 2004; Liebezeit and Dubaish, 2012; Mathalon and Hill, 2014; Dekiff et al., 2014). Many plastic debris strands have been observed on the high tide line during receding tides (McDermid and McMullen, 2004; Thiel et al., 2013). The accumulation of microplastic at the low tide line due to deposition in low energy environments has also been observed (Mathalon and Hill, 2014).

Coastal wetlands (e.g., mangroves, tidal marshes, swamps) might be a very important reservoir of microplastics that has been inadequately investigated due to limited monitoring data. The dense vegetation of wetlands may effectively retain microplastics floating on the surface (Sutton et al., 2016). High concentrations of organic matter and sediments in the water column can accelerate the aggregation and biofouling of microplastic and result in the deposition in sediments. A survey of microplastics in wetlands might drastically revise our estimation of the standing stocks of plastics in the marine environment (Nor and Obbard, 2014).

Coastal morphological features (e.g., lagoons, island barriers, tidal flats, barrier reefs, sand dunes) and coastal engineering structures (e.g., breakwater, groin, sea walls, harbors) can also affect microplastics transport. For example, a modeling study by Critchell et al. $(2015,2016)$ demonstrated that beach orientation to the prevailing wind direction affected the accumulation rate of debris and wind shadow of island barriers, which affected the resuspension of particles. It has also been suggested that microplastics might be trapped inside harbors due to the enclosed geometry (Claessens et al., 2011; Mathalon and Hill, 2014). An investigation in a lagoon in Venice, Italy indicated that the spatial distribution of sediment microplastics was related to the morphology of the lagoon (Vianello et al., 2013).

\section{Transport in coastal seas}

In open seas, buoyant microplastics either float in the surface microlayer (Cózar et al., 2014) or are suspended in the water column (Kukulka et al., 2012, 2016; Isobe et al., 2014; Enders et al., 2015). In many aspects, buoyant microplastics act like passive tracers and are transported in the direction of ocean currents and wind/waves. Many studies have been conducted to study the transport mechanisms of floating plastics in oceans (Kubota, 1994; Martinez et al., 2009; Law et al., 2010, 2014; Kukulka et al., 2012, 2016; Howell et al., 2012; Potemra, 2012; Cózar et al., 2014; Eriksen et al., 2013) and regional seas (Yoon et al., 2010; Kako et al., 2011, 2014; Neumann et al., 2014; Isobe et al., 2014; Mansui et al., 2015; Critchell et al., 2015; Liubartseva et al., 2016).

\subsection{Surface currents}

Surface current are the major force enabling the long-distance transport of microplastics from coasts to open oceans. Global ocean circulation driven by wind and thermohaline processes form five subtropical gyres that accumulate large amounts of plastic debris, which has caused extensive ecological concern (Law et al., 2010, 2014; Cózar et al., 2014). Numerical modeling studies have independently predicted similar centers of accumulation in the gyres created by wind-driven Ekman transport and geostrophic circulation (Maximenko et al., 2012; Lebreton et al., 2012; van Sebille et al., 2012). Boundary currents (e.g., Gulf Stream and Kuroshio) along the continental shelves have long been recognized as a major pathway of terrestrial material, including microplastic, into open oceans. Floating microplastic can be transported very rapidly $\left(>2 \mathrm{~km} \mathrm{~h}^{-1}\right)$ in boundary currents (Thiel and Gutow, 2005). Surface plastic concentrations measured in the Kuroshio can become exceptionally high because of their proximity to densely populated Asian coasts (Yamashita and Tanimura, 2007).

Coastal currents have a larger temporal variability and their capabilities for transporting microplastics from the coastline to continental shelf might be affected by seasonal variations in upwelling/downwelling, vertical stratification, and weather disturbances. Recently, numerical modeling has been carried out to explore the source-sink relationships at a regional scale (Table 2). The simulation results showed that floating plastics free from nearshore trapping are carried to the continental shelf by coastal currents regulated by winds, waves, and land formations. Unlike in the open ocean, there is no permanent sea surface structure capable of accumulating floating items in the long-term (Mansui et al., 2015; Frère et al., 2017), which agrees with field survey data (Cózar et al., 2015). Studies often indicate that coastal "hot spots" with seasonal features result from seasonal variability of coastal circulations and proximity to plastic sources (Cózar et al., 2015; Liubartseva et al., 2016).

Oceanographic features, such as fronts or eddies, can influence the dispersal and distribution of floating microplastics in coastal seas. Accumulation occurs on fronts between two different water masses or in waters streaming around formations such as islands, reefs, and peninsulas (Wolanski and Elliott, 2015). Mesoscale eddies emerging from instabilities of horizontal density gradients or sheared motion may accumulate or repel floating and suspended 


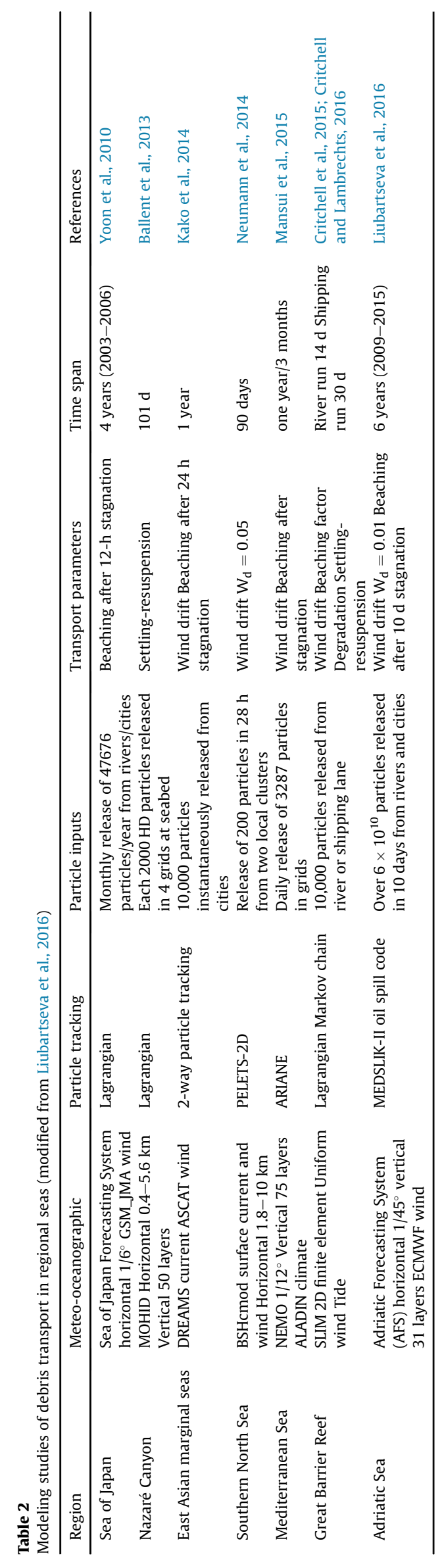

materials, depending on their spin direction. The propagation of eddies associated with the seasonal movement of subtropical gyres may transport microplastics within the eddy patches (Howell et al., 2012).

\subsection{Wind and wave induced drift}

In addition to wind-induced Ekman circulation, wind may also directly affect the trajectory and velocity of plastic floating on the ocean surface. The impact of leeway drift or windage may result in the flow path and speed of plastic particles differing from that of the surface current alone (Breivik et al., 2011). The exact course of wind drift depends on the wind conditions as well as the buoyancy properties (density, size, and shape) of drifting particles. The effect of wind on the speed and direction of floating plastics is rather challenging to predict due to the uncertainty in the buoyancy of plastic particles.

For plastic particles floating in the field of surface waves, Stokes drift may be important for their movement. Floating particles on the surface experience a net Stokes drift velocity in the direction of wave propagation, which may reach $1 \%$ of the wind speed. In real ocean conditions, wave-induced Stokes drift and direct windage are both propagated in the direction of wind and are difficult to account for separately. Thus, it is more convenient to lump the movement by Stokes drift into the wind drift process (Kubota, 1994; Liubartseva et al., 2016). However, in shallow coastal waters, nonlinear wave breaking can cause onshore mass transport and return plastic particles onshore (Isobe et al., 2014).

Buoyant plastic particles may move much faster than surface currents under open ocean conditions. Simplified approaches have been proposed to use wind drift coefficients to measure the drag forces of wind in modeling the dispersal of floating objects (Critchell et al., 2015; Chubarenko et al., 2016; NOAA, 2016). Here, the floating velocity of a particle $\left(\vec{U}_{P}\right)$ is calculated as follows:

$\overrightarrow{U_{P}}=\overrightarrow{U_{A}}+\overrightarrow{U_{D}}+\overrightarrow{U_{W}}$

where advection with the surface current $\left(\vec{U}_{A}\right)$ can be computed using hydrodynamic models. Random walk $\left(\overrightarrow{U_{D}}\right)$ caused by horizontal turbulent mixing and can be estimated as follows:

$\overrightarrow{U_{D}}=\xi \sqrt{\frac{2 \vec{K}_{H}}{\Delta t}}$

where $\Delta t$ is the computation time step, $\xi$ is a random coefficient ranging from -1 to 1 , and $\overrightarrow{K_{H}}$ is the horizontal eddy mixing parameter that is related to the scale of turbulence.

Wind drift $\left(\overrightarrow{U_{W}}\right)$ is commonly calculated using a simplified linear function as follows:

$\overrightarrow{\mathrm{U}_{\mathrm{W}}}=\mathrm{W}_{\mathrm{d}} \overrightarrow{\mathrm{V}_{\mathrm{W}}}$

where $W_{d}$ is the wind drift coefficient measuring the degree to which the wind influences the floating particles, and $\overrightarrow{V_{W}}$ is the near-surface wind velocity field. The wind drift coefficient is normally empirically decided using values ranging from 0.01 to 0.06 (Kako et al., 2011; Maximenko et al., 2012; Liubartseva et al., 2016). Sensitivity analyses, over a range of values $(0.01,0.02$ and 0.04$)$, have been carried out by Critchell and Lambrechts (2016), and the results have demonstrated the importance of wind drift processes in the movement of large buoyant particles. A theoretical calculation on spherical particles by (Chubarenko et al., 2016) result a very 
high drifting velocity for polystyrene $\left(\sim 0.05 \mathrm{~g} \mathrm{~cm}^{-3}\right)$ and polyethylene $\left(\sim 0.95 \mathrm{~g} \mathrm{~cm}^{-3}\right)$ particles. However, their formula suggests that the wind drift does not depend on the particle size, which is not applicable to real ocean conditions since smaller particles tend to be mixed vertically in the water column under stormy conditions through Langmuir circulation. Submerged plastic particles have no exposure to the wind and hence no wind drift should be assumed (Reisser et al., 2015).

\subsection{Turbulent vertical mixing}

In addition to moving horizontally under forcing from wind waves, and currents, buoyant microplastics are also transported vertically in the water column by turbulent forces. Recent studies have suggested that vertical mixing considerably affects the population and size distribution of plastics. Therefore, traditional surface measurements have severely underestimated the total plastics concentrations in oceans, and a reinterpretation of existing plastic marine debris datasets is required (Kukulka et al., 2012; Desforges et al., 2014; Reisser et al., 2015; Enders et al., 2015; Kukulka et al., 2016; Kooi et al., 2016).

Substantial vertical mixing implies that large fractions of buoyant microplastics are transported much slower as suspended particles than through surface floatation pathways. In general, vertical mixing tended to increase with particle density and to decrease with particle size. This led to preferential removal of heavier and smaller plastic particles from the sea surface (Ballent et al., 2012; Reisser et al., 2015; Cózar et al., 2014). Since the subsurface currents are normally much lower than the surface currents and are devoid of influences from wind and surface waves, microplastic particles generally have a much longer residence time than mesoplastics and macroplastics. Modeled vertical distribution shows that particles $1 \mathrm{~mm}$ or larger remain in the surface layer $(<1 \mathrm{~m})$, whereas particles of $100 \mu \mathrm{m}$ and $10 \mu \mathrm{m}$ are nearly uniformly distributed above the pycnocline and rapidly approach zero below that (Enders et al., 2015). Vertical mixing of plastics has been considered to be controlled by wind-induced turbulence, such as breaking waves and Langmuir circulations, and the mixing length is dependent on the mixed layer depth (Kukulka et al., 2012). Langmuir turbulence due to the interaction between the surface current and surface waves can facilitate deep submergence of buoyant particles. Recently, it was demonstrated that diurnal heating cycles in the surface boundary layer can enhance turbulent downward mixing at night (Kukulka et al., 2016). Furthermore, vertical mixing can lead to deposition to the sea bottom and increase sediment retention of microplastic particles, which is particularly important in coastal seas where the surface mixing layer can reach the sea bottom.

The vertical distribution of microplastics is a function of terminal velocity $(w)$ and a vertical turbulent mixing coefficient $(K z)$. The terminal velocity of microplastics can be positive $\left(\rho_{p}<\rho_{\mathrm{w}}\right)$ or negative $\left(\rho_{p}>\rho_{\mathrm{w}}\right)$ (Khatmullina and Isachenko, 2017). At low Reynold numbers $\left(\operatorname{Re}=\frac{\rho_{w} w d}{\eta}\right)$, the terminal velocity of spherical particles can be estimated as a function of particle density and particle size based on Stokes' Law:

$w=\frac{\left(\rho_{w}-\rho_{p}\right) \operatorname{gd}^{2}}{18 \eta}$

where $\eta$ is the seawater viscosity, and $\mathrm{g}$ is the gravitational acceleration. At a high Reynolds number, terminal velocity $(w)$ is defined at a steady state, where gravitational force $\left(F_{g}\right)$ equals hydrodynamic drag $\left(F_{D}\right)$, as follows:

$$
\begin{gathered}
F_{g}=\frac{\left(\rho_{w}-\rho_{p}\right) g \pi \mathrm{d}^{3}}{6} \\
F_{D}=\frac{\pi C_{d} \rho_{w} d^{2} w|w|}{8}
\end{gathered}
$$

The drag coefficient $\left(C_{d}\right)$ is a dimensionless parameter that can be empirically related to the Reynolds number $(\operatorname{Re})$ (Enders et al., 2015):

$C_{D}=\frac{24}{R e}+\frac{5}{\sqrt{R e}}+\frac{2}{5}$

Setting Eq. (5) equal to Eq. (6) can obtain the following:

$w^{2}\left(\frac{24 \mu}{\rho_{w} d w}+5 \sqrt{\frac{\mu}{\rho_{w} d w}}+\frac{2}{5}\right)=\frac{4}{3} \frac{\left(\rho_{w}-\rho_{p}\right) g d}{\rho_{w}}$

From Eq. (8), the terminal velocity can be calculated for particles with varying $\rho_{p}$ and $\mathrm{d}$. Laboratory experiments have examined the terminal velocity as a function of the physical properties (density, size, shape) of microplastics, and the results generally conform with theoretical calculations, with some variance (Kowalski et al., 2016; Khatmullina and Isachenko, 2017).

Under strong turbulence conditions, the vertical movement of microplastics can be estimated with a combination of the terminal velocity and random walk (Isobe et al., 2014), as follows:

$\mathrm{U}_{\mathrm{z}}=\mathrm{w}+\xi \sqrt{\frac{2 \mathrm{~K}_{\mathrm{z}}}{\Delta \mathrm{t}}}$

where $K_{z}$ is the vertical turbulent mixing coefficient that needs to be estimated from turbulence closure algorithms (Enders et al., 2015). Combine Eq. (1) with Eq. (9), and the transport of particles in three-dimensional space can be dynamically predicted from microplastics characterization $\left(\rho_{p}, \mathrm{~d}\right)$ and ocean hydrodynamic conditions $\left(\overrightarrow{U_{A}}, \overrightarrow{U_{W}}, \overrightarrow{K_{H}}, K_{z}\right)$.

\section{Benthic transport}

Marine sediment is the ultimate sink for most microplastics released into coastal seas. High-density plastics are naturally nonbuoyant and will eventually be caught in sediment. Coagulation with natural suspended particles or fouling with microbial organisms can increase the density and size of floating particles and cause their deposition onto the sea bed. High concentrations of microplastics have been observed at the bottom of coastal seas and deep oceans throughout the world (e.g., Galgani et al., 2000; Thompson et al., 2004; Hidalgo-Ruz et al., 2012; Woodall et al., 2014; van Cauwenberghe et al., 2013, 2015). Therefore, it is critical to understand the rate and amount of microplastics deposition and entrainment in the bottom layer to fully evaluate the environmental fate and risk from plastic pollution. Unfortunately, little is known about the behavior of microplastics in the benthic environment due largely to the limitation in sampling and observation techniques (Ballent et al., 2012, 2013; Kowalski et al., 2016; Chubarenko et al., 2016).

Non-buoyant microplastic particles may transport as bedload or suspended load, depending on the benthic shear stress applied over the sediment-water interface. Over the long term, an ocean area with hydrodynamic conditions favorable for sediment deposition (i.e., depocenter) may function as a major terminal sink for plastics (Shimanaga and Yanagi, 2016; Alomar et al., 2016). Current analysis on benthic transport draws largely on the analogy of well-studied 
sediment transport processes. A major difference is that plastics have a range of specific densities $\left(0.8-1.4 \mathrm{~g} \mathrm{~cm}^{-3}\right)$ that are lower than inorganic sediments $\left(2.65 \mathrm{~g} \mathrm{~cm}^{-3}\right)$. Thus, microplastics are more mobile and have a much longer residence time in the water column than that of suspended loads.

\subsection{Deposition}

Although an overwhelming volume of literature has reported the almost ubiquitous distribution of microplastic in sediments, there is scarce knowledge regarding the deposition of microplastic. Only recently, theoretical calculation and laboratory experiments have been carried out to determine the settling velocity of high density microplastics (Ballent et al., 2012, 2013; Kowalski et al., 2016; Chubarenko et al., 2016). Marine snow might be the main vessel for the vertical transport of microplastics through the water column to the sea floor. (van Cauwenberghe et al., 2013; Woodall et al., 2014). Biologically facilitated aggregation (e.g., colonization by microorganisms, attachment to phytoplankton, and flocculation with organic and inorganic matter) forms flocs in suspension with higher density and larger particle size. The sinking rates of aggregates could reach hundred meters per day, compared with microplastics with settling rates $<4 \mathrm{~mm} \mathrm{~d}^{-1}$ (Long et al., 2015).

A better understanding of the deposition process needs to be based on in-situ measurements of settling flux. So far, plastics have not been observed as a significant component of the material collected in sediment traps installed in the open ocean (Law et al., 2010). A large array of well-designed sediment traps in coastal seas under different hydrodynamic conditions is necessary to determine the spatial and temporal pattern of microplastic deposition.

Given that coastal seas are dynamic systems with a continuous input of suspended particles, microplastics may become buried in the sediment during periods of accretion (Costa et al., 2011; Moreira et al., 2016). An evaluation of the three-dimensional position of microplastics within marine sediments in Santos Bay, Brazil, which provided evidence that the burial of microplastics might be related to high energy oceanographic events, such as sea storms (Turra et al., 2014). The vertical stratification of sediments indicated that microplastics might accumulate in similar ways as organic detritus particles that need to be examined with stratified samples using cores.

\subsection{Resuspension}

High-density microplastics can remain in suspension for extended periods due to turbulent ocean conditions, and benthic microplastics may be re-suspended from turbulent flows (Ballent et al., 2013). Storms have long been recognized as the dominant physical forcing of bottom sediment resuspension with a combination of wind-forced and storm wave-associated currents. In many estuaries, the tidal current is the dominant force creating strong shear stress. Large-amplitude internal waves can trigger instabilities in the bottom boundary layer and contribute to particle resuspension.

Critical shear stress is a function of the particle size and density and is normally experimentally determined under a simulated benthic shear environment. Using an erosion microcosm, Ballent et al. (2013) measured the critical shear stress of benthic microplastics and found that bed load transport commenced at $\tau=0.014 \mathrm{~N} \mathrm{~m}^{-2}$, and approximately $75 \%$ of pellets were in suspension at $\tau=0.14 \mathrm{~N} \mathrm{~m}^{-2}$. Laboratory experiments are warranted to construct Shield curves for different plastic types and turbulence conditions. Rapidly developing particle image velocity technology has provided an efficient method of studying the resuspension and transport of particles in turbulent conditions (Raffel et al., 2013) and needs to be explored to quantitatively investigate the benthic movement of microplastic particles.

\section{Biological interactions}

The behavior of microplastics in coastal seas with high primary productivity is more complex due to the interaction of particles with a wide range of marine organisms from bacteria to large mammals. Biofouling by microbes, algae and invertebrates can increase the density of microplastics and cause their eventual sink into the benthos. The ecological risk of microplastic ingestion by zooplankton, benthic organisms, and large marine animals are largely dependent on transport pathways.

\subsection{Biofouling}

Plastics can rapidly develop surface fouling by accumulating microbial films, followed by colonization with algae and invertebrates (Andrady, 2011; Cole et al., 2011; Muthukumar et al., 2011; Fazey and Ryan, 2016b). With increased film thickness, the particle size and particle density of plastics also increases (Chubarenko et al., 2016). Consequently, the initially buoyant particles might sink below the water surface and become neutrally or negatively buoyant. Fouling of plastic particles has been observed in field surveys and was proposed as the cause for the increased density of microplastics in the open ocean (Morét -Ferguson et al., 2010; Cózar et al., 2014). The kinetics of biofouling depends on the particle size and surface area of microplastics, water condition, and biological activities (Muthukumar et al., 2011). Microplastics with high surface areas and high porosity might have a higher rate of biofouling and may sink sooner than large items (Ryan, 2015). Theoretical calculation by Chubarenko et al. (2016) demonstrated that the timing of particle fouling to sink is directly proportionate to their diameter, which empirically agrees with the observation that smaller particles have a higher rate of biofouling and is reported more often in marine sediments. Under the same water conditions, the biofouling rate of different shapes of particles with the same characteristic scale follows the order of films $>$ fibers $>$ spheres. It should be noted that the biochemical conditions (e.g., temperature, photosynthetically active radiation, nutrients availability) of sea water are important factors regulating the biofouling process and need to be systematically studied. De-fouling by foraging organisms might increase the buoyancy of microplastic particles and return them to the sea surface. As a result, microplastics may occupy different positions in the water column at different times (Andrady, 2011). Eventually, the biofouling of microplastics causes particles to sink to the benthos and makes them available to deposit feeders and detritivores (Wright et al., 2013).

\subsection{Ingestion}

A major ecological risk from microplastic is ingestion by marine organisms (filter, suspension and detritus feeders, invertebrates, fish, turtles, and marine mammals) and accumulation in the marine food web. The size of microplastics is close to that of planktons and within the optimal prey range for many marine animals. Laboratory feeding studies have shown that marine organisms such as invertebrates, polychaetes, bivalves, echinoderms and copepods could take up microplastics from the environment (Cole et al., 2011; Thompson et al., 2004). Suspension and filter feeders are at particularly high risk of microplastic ingestion, as their feeding modes are used to concentrate small particles from large volumes of water. In addition to the feeding mode and anatomy of the consumers, the extent of plastic ingestion depends on factors such as particle size, abundance, aggregation, and position in water 
column and sediment. Concentrations of microplastics in marine animals are positively correlated with the available plastics in seawater and are inversely related to particle size. Incorporation into marine aggregates may change the bioavailability of microplastics to marine organisms (Wright et al., 2013).

Transport of microplastics into sea water and sediment has important implications for their bioavailability for various species of marine organisms. The residence time of microplastics in the water column determines the potential chance of being ingested by zooplankton, neuston, and fish. The ubiquitous presence of microplastics in benthic sediments indicates their potential availability to macrobenthic organisms. A realistic evaluation of the ecological risks of microplastics must consider the temporal and spatial distribution of microplastics in water and sediments.

\section{Numerical simulations}

Mathematical models based on the principals of fluid mechanics have provided an effective technique for in-depth investigation of the movement of microplastic particles under various hydrodynamic settings (Hardesty et al., 2017). The fundamental physical mechanisms formulated in Eqs. (1)-(9) can be incorporated into numerical models to simulate microplastic transport. However, a comprehensive modeling framework needs to incorporate additional mechanisms that are unique and critical for microplastic transport. For example, the dynamic change in particle density and size distribution needs to be explicitly described to account for the sink mechanisms due to biofouling and aggregation. Key parameters (e.g., equivalent particle size, critical shear stress) determining the transport pathways (pelagic vs. benthic) need to be expressed as a function of microplastic characteristics. Microplastic-shoreline interaction should be prescribed based on coastal geomorphology and hydrodynamic conditions. Some recommendations for future improvement in modeling microplastic transport were provided by (Hardesty et al., 2017).

Accurate hydrodynamic data are fundamental to the successful modeling of the fate and behavior of microplastics. An extensive suite of research tools, including remote sensing, global drifter array, and numerical modeling has been successfully applied to describe and predict the transport route of floating plastics. Satellite observations of sea surface wind, altimetry, temperature, and salinity, as well as derived global surface current products (e.g., OSCAR, AVISO) provide a rich dataset to estimate the flow path of plastic debris on the ocean's surface. Global and regional arrays of drifters provide direct measurements of large-scale global and basin-wide ocean currents, as well as mesoscale ocean eddies (Martinez et al., 2009; Maximenko et al., 2012; van Sebille et al., 2012; Carson et al., 2013). Meteorological datasets, such as satellite remote-sensing data (NASA's Quikscat/Seawinds and ESA's ERS$1 / 2$ ) and reanalysis datasets [National Centers for Environmental Prediction (NCEP) from NOAA and the European Centre for Medium-Range Weather Forecasts (ECMWF)] provided critical wind/wave data for numerical simulation. An ocean general circulation model (e.g., HYCOM) with data assimilation capabilities provided a reanalysis dataset of 3-D ocean currents and water properties at a fine scale $\left(1 / 12^{\circ}\right)$. Numerical models have been developed in recent years to predict the transport trajectory of floating debris in open seas with contributions from geostrophic currents, Ekman drift, Stokes drift, and thermohaline circulation (NOAA, 2016).

The numerical simulation of plastic transport commonly employs the Lagrangian particle tracking approach to calculate the trajectory of individual particles over time (Table 2). The method relies on hydrodynamic inputs (current velocities, temperature/ salinity) obtained from independent ocean circulation models
(NOAA, 2016). For instance, Ballent et al. (2012, 2013) utilized a MPHID hydrodynamic model coupled with a Lagrangian transport module to simulate the transport of benthic microplastic in the Nazare Canyon (Portugal) and revealed the tidal-driven short-range reciprocating movement along the canyon and occasional mass transport down canyon because of storm and internal wave action. Critchell and Lambrechts (2016) demonstrated the use of an advection-diffusion model to evaluate beaching, settlingresuspension, degradation and topographic effects in governing plastic accumulation. Their studies indicate that a lack of proper parameterization hindered the use of such models for practical applications in making management decisions. Due to the stochastic nature of microplastic transport, large uncertainties in modeling results are commonly observed and need to be quantified. Another major limitation for the application of numerical simulation is the difficulty in calibrating and validating the simulation results, since the lack of standardized monitoring data prohibits a direct comparison between the model outputs and field observations (Liubartseva et al., 2016).

Numerical models have the advantage of conducting a scenario analysis to evaluate the relative contribution of transport mechanisms and to predict the potential transport pathways under changed climatic conditions (Hardesty et al., 2017). A global model of floating microplastic was applied to simulate different cleanup scenarios and identified China and Indonesia's coasts as the optimal removal locations (Sherman and Van Sebille, 2016). Another important application of the numerical transport model is to identify the potential sources of plastics in the ocean (Isobe et al., 2009). developed a two-way (backward-in-time and forward-intime) particle-tracking method to statistically locate the potential sources of drifting objects and successfully applied the model to the East China Sea. A similar method was used by Liubartseva et al. (2016) to quantitatively construct a source-receptor matrix in different regions of the Adriatic Sea, which was a valuable tool for stakeholders and policy makers to address plastic pollution issues. Furthermore, numerical models have the capability to project future distribution patterns under changing climate and circulation patterns. Sea level rise, sea ice melt, changing precipitation patterns and storm frequency/intensity, and variation in the thermohaline conditions are factors that may impact plastics distribution and accumulation in the marine environment and need to be assessed using numerical models (Welden and Lusher, 2017). The development and application of numerical models will greatly expand our capability to more accurately evaluate the environmental risks and effectively deploy management strategies to alleviate the impact of microplastic pollution.

\section{Concluding remarks}

Transport in coastal environments is one of the major processes controlling the environmental fate and risks from microplastics because it regulates their spatial and temporal distribution among various marine habitats. Physical characteristics determined the mobility of plastics as follows: 1) low density large particles can spend a long time at the sea surface until they lose buoyancy through aggregation/biofouling; 2) high-density particles ultimately sink to sea bottom where they may transport as bed load or suspended load, depending on bottom boundary layer turbulence; and 3) a large portion of microplastics suspend in the upper-ocean mixing layer and move both horizontally and vertically with hydrodynamic forces. Field survey results strongly suggest that a dominant share of the plastic supplied to the marine environment is retained nearshore in estuarine, beach, and wetland sediments, although the physical mechanisms of this process have not been investigated. Questions regarding the fate and behavior of 
microplastics that need to be answered include, but are not limited to, the following: 1) what is an effective way to quantify microplastic fluxes from the coast to the open sea? 2) How does the sediment flux of microplastics vary with particle density and size distribution, bottom boundary layer turbulence, and benthic sediment characteristics? 3) What are dominant hydrodynamic forces determining the residence time of plastic particles in the water column at different temporal and spatial scales? and 4) What role does fragmentation, aggregation, and biofouling play in controlling the dynamic distribution of plastics in the water column and sediment?

\section{Acknowledgements}

This research was financially supported by the National Key Research and Key Development Plan of China (2016YFC1402202) and the Key International Cooperation Program of the Chinese Academy of Sciences (KYSB20160003). I would like to thank Drs. Eric Wolanski, Yongming Luo, Daoji Li, Haibo Zhang, Hui Wu, Yanfang Li, Cheng Tang and Mr. Jia Li for their constructive discussion and comments on the manuscript.

\section{References}

Acha, E.M., Mianzan, H.W., Iribarne, O., Gagliardini, D.A., Lasta, C., Daleo, P., 2003. The role of the Rio de la Plata bottom salinity front in accumulating debris. Mar. Pollut. Bull. 46, 197-202.

Alomar, C., Estarellas, F., Deudero, S., 2016. Microplastics in the Mediterranean Sea: deposition in coastal shallow sediments, spatial variation and preferential grain size. Mar. Environ. Res. 115, 1-10.

Andrady, A.L., 2011. Microplastics in the marine environment. Mar. Pollut. Bull. 62, 1596-1605.

Auta, H.S., Emenike, C.U., Fauziah, S.H., 2017. Distribution and importance of microplastics in the marine environment: a review of the sources, fate, effects, and potential solutions. Environ. Int. 102, 165-176.

Bakir, A., Rowland, S.J., Thompson, R.C., 2014. Transport of persistent organic pollutants by microplastics in estuarine conditions. Estuar. Coast. Shelf Sci. 140, 14-21.

Ballent, A., Purser, A., Mendes, P.D.J., Pando, S., Thomsen, L., 2012. Physical transport properties of marine microplastic pollution. Biogeosci. Discuss. 9, 18755.

Ballent, A., Pando, S., Purser, A., Juliano, M.F., Thomsen, L., 2013. Modelled transport of benthic marine microplastic pollution in the Nazare Canyon. Biogeosci 10, 7957-7970.

Barnes, D.K.A., Galgani, F., Thompson, R.C., Barlaz, M., 2009. Accumulation and fragmentation of plastic debris in global environments. Philos. Trans. R. Soc. B 364, 1985-1998.

Becherer, J., Flöser, G., Umlauf, L., Burchard, H., 2016. Estuarine circulation versus tidal pumping: sediment transport in a well-mixed tidal inlet. J. Geophys. Res. Oceans 121, 6251-6270.

Besseling, E., Quik, J.T., Sun, M., Koelmans, A.A., 2017. Fate of nano-and microplastic in freshwater systems: a modeling study. Environ. Pollut. 220, 540-548.

Breivik, Ø., Allen, A.A., Maisondieu, C., Roth, J.C., 2011. Wind-induced drift of objects at sea: the leeway field method. Appl. Ocean. Res. 33, 100-109.

Browne, M.A., Galloway, T.S., Thompson, R.C., 2010. Spatial patterns of plastic debris along estuarine shorelines. Environ. Sci. Technol. 44, 3404-3409.

Browne, M.A., Crump, P., Niven, S.J., Teuten, E., Tonkin, A., Galloway, T., Thompson, R.C., 2011. Accumulation of microplastic on shorelines worldwide: sources and sinks. Environ. Sci. Technol. 45, 9175-9179.

Carpenter, E.J., Anderson, S.J., Harvey, G.R., Miklas, H.P., Peck, B.B., 1972. Polystyrene spherules in coastal waters. Science 178, 749-750.

Carson, H.S., Lamson, M.R., Nakashima, D., Toloumu, D., Hafner, J., Maximenko, N., McDermid, K.J., 2013. Tracking the sources and sinks of local marine debris in Hawaii. Mar. Environ. Res. 84, 76-83.

Cheung, P.K., Cheung, L.T.O., Fok, L., 2016. Seasonal variation in the abundance of marine plastic debris in the estuary of a subtropical macro-scale drainage basin in South China. Sci. Total Environ. 562, 658-665.

Chubarenko, I., Bagaev, A., Zobkov, M., Esiukova, E., 2016. On some physical and dynamical properties of microplastic particles in marine environment. Mar. Pollut. Bull. 108, 105-112.

Chubarenko, I., Stepanova, N., 2017. Microplastics in sea coastal zone: lessons learned from the Baltic amber. Environ. Pollut. 224, 243-254.

Claessens, M., De Meester, S., Van Landuyt, L., De Clerck, K., Janssen, C.R., 2011. Occurrence and distribution of microplastics in marine sediments along the Belgian coast. Mar. Pollut. Bull. 62, 2199-2204.

Cole, M., Lindeque, P., Halsband, C., Galloway, T.S., 2011. Microplastics as contaminants in the marine environment: a review. Mar. Pollut. Bull. 62, 2588-2597.

Collignon, A., Hecq, J.H., Glagani, F., Voisin, P., Collard, F., Goffart, A., 2012. Neustonic microplastic and zooplankton in the north western mediterranean sea. Mar. Pollut. Bull. 64, 861-864.

Costa, M.F., Silva-Cavalcanti, J.S., Barbosa, C.C., Portugal, J.L., Barletta, M., 2011 Plastics buried in the inter-tidal plain of a tropical estuarine ecosystem. SI.64 J. Coast. Res. 339-343.

Cózar, A., Echevarría, F., González-Gordillo, J.I., Irigoien, X., Úbeda, B., HernándezLeón, S., Palmae, A.T., Navarrof, S., García-de-Lomasa, J., Ruizg, A., Fernández-dePuelles, M.L., Duartei, C.M., 2014. Plastic debris in the open ocean. PNAS 111, 10239-10244.

Cózar, A., Sanz-Martin, M., Marti, E., Gonzalez-Gordillo, I., Ubeda, B., Galvez, J. Irigoien, X., Duarte, C., 2015. Plastic accumulation in the mediterranean sea. PLoS One 10, 1-12 e0121762.

Critchell, K., Grech, A., Schlaefer, J., Andutta, F.P., Lambrechts, J., Wolanski, E. Hamann, M., 2015. Modelling the fate of marine debris along a complex shoreline: lessons from the Great Barrier Reef. Estuar. Coast. Shelf Sci. 167 414-426.

Critchell, K., Lambrechts, J., 2016. Modelling accumulation of marine plastics in the coastal zone; what are the dominant physical processes? Estuar. Coast. Shelf Sci. $171,111-122$.

Dekiff, J.H., Remy, D., Klasmeier, J., Fries, E., 2014. Occurrence and spatial distribution of microplastics in sediments from Norderney. Environ. Pollut. 186, 248-256.

Desforges, J.P.W., Galbraith, M., Dangerfield, N., Ross, P.S., 2014. Widespread distribution of microplastics in subsurface seawater in the NE Pacific Ocean. Mar. Pollut. Bull. 79, 94-99.

do Sul, J.A.I., Costa, M.F., 2014. The present and future of microplastic pollution in the marine environment. Environ. Pollut. 185, 352-364.

Eerkes-Medrano, D., Thompson, R.C., Aldridge, D.C., 2015. Microplastics in freshwater systems: a review of the emerging threats, identification of knowledge gaps and prioritisation of research needs. Water Res. 75, 63-82.

Enders, K., Lenz, R., Stedmon, C.A., Nielsen, T.G., 2015. Abundance, size and polymer composition of marine microplastics $\geq 10 \mu \mathrm{m}$ in the Atlantic Ocean and their modelled vertical distribution. Mar. Pollut. Bull. 100, 70-81.

Eriksen, M., Maximenko, N., Thiel, M., Cummins, A., Lattin, G., Wilson, S., Hafner, J. Zellers, A., Rifman, S., 2013. Plastic pollution in the South Pacific subtropical gyre. Mar. Pollut. Bull. 68, 7176.

Eriksson, C., Burton, H., Fitch, S., Schulz, M., van den Hoff, J., 2013. Daily accumulation rates of marine debris on sub-Antarctic island beaches. Mar. Pollut. Bull. 66, 199-208.

Fazey, F.M., Ryan, P.G., 2016a. Debris size and buoyancy influence the dispersal distance of stranded litter. Mar. Pollut. Bull. 110, 371-377.

Fazey, F.M., Ryan, P.G., 2016b. Biofouling on buoyant marine plastics: an experimental study into the effect of size on surface longevity. Environ. Pollut. 210, $354-360$.

Filella, M., 2015. Questions of size and numbers in environmental research on microplastics: methodological and conceptual aspects. Environ. Chem. 12, 527-538.

Fok, L., Cheung, P.K., 2015. Hong Kong at the Pearl River Estuary: a hotspot of microplastic pollution. Mar. Pollut. Bull. 99, 112-118.

Fok, L., Cheung, P.K., Tang, G., Li, W.C., 2017. Size distribution of stranded small plastic debris on the coast of Guangdong, South China. Environ. Pollut. 220, 407-412.

Frère, L., Paul-Pont, I., Rinnert, E., Petton, S., Jaffré, J., Bihannic, I., Soudant, P., Lambert, C., Huvet, A., 2017. Influence of environmental and anthropogenic factors on the composition, concentration and spatial distribution of microplastics: a case study of the Bay of Brest (Brittany, France). Environ. Pollut. 225, $211-222$.

Galgani, F., Leaute, J., Moguedet, P., Souplet, A., Verin, Y., Carpentier, A., Goraguer, H., Latrouite, D., Andral, B., Cadiou, Y., 2000. Litter on the sea floor along European coasts. Mar. Pollut. Bull. 40, 516e527.

Galloway, T.S., Cole, M., Lewis, C., 2017. Interactions of microplastic debris throughout the marine ecosystem. Nat. Ecol. Evol. 1, 0116.

GESAMP, 2015. Sources, fate and effects of microplastics in the marine environment: a global assessment. (Kershaw, P. J., ed.). (IMO/FAO/UNESCO-IOC/UNIDO/ WMO/IAEA/UN/UNEP/UNDP Joint Group of Experts on the Scientific Aspects of Marine Environmental Protection). Rep. Stud. GESAMP No. 90, 96 p. http://ec europa.eu/environment/marine/good-environmental-status/descriptor-10/pdf/ GESAMP_microplastics\%20full\%20study.pdf.

Hardesty, B.D., Harari, J., Isobe, A., Lebreton, L., Maximenko, N., Potemra, JT., van Sebille, K., Vethaak, D., Wilcox, C., 2017. Using numerical model simulations to improve the understanding of micro-plastic distribution and pathways in the marine environment. Front. Mar. Sci. 4, 30.

Harshvardhan, K., Jha, B., 2013. Biodegradation of low-density polyethylene by marine bacteria from pelagic waters, Arabian Sea, India. Mar. Pollut. Bull. 77, 100-106.

Heo, N.W., Hong, S.H., Han, G.M., Hong, S., Lee, J., Song, Y.K., Jang, M., Shim, W.J., 2013. Distribution of small plastic debris in cross-section and high strandline on Heungnam beach, South Korea. Ocean. Sci. J. 48, 225-233.

Herman, P.M., Heip, C.H., 1999. Biogeochemistry of the MAximum TURbidity zone of estuaries (mature): some conclusions. J. Mar. Syst. 22, 89-104.

Hidalgo-Ruz, V., Gutow, L., Thompson, R.C., Thiel, M., 2012. Microplastics in the marine environment: a review of the methods used for identification and quantification. Environ. Sci. Technol. 46, 3060-3075.

Howell, E.A., Bograd, S.J., Morishige, C., Seki, M.P., Polovina, J.J., 2012. On North Pacific circulation and associated marine debris concentration. Mar. Pollut. Bull. 
$65,16-22$

Isobe, A., Kako, S., Chang, P.H., Matsuno, T., 2009. Two-way particle tracking model for specifying sources of drifting objects: application to the East China Sea shelf. J. Atmos. Ocean. Technol. 26, 1059-1064.

Isobe, A., Kubo, K., Tamura, Y., Nakashima, E., Fujii, N., 2014. Selective transport of microplastics and mesoplastics by drifting in coastal waters. Mar. Pollut. Bull 89, 324-330.

Jambeck, J.R., Geyer, R., Wilcox, C., Siegler, T.R., Perryman, M., Andrady, A., Narayan, R., Law, K.L., 2015. Plastic waste inputs from land into the ocean. Science 347, 768-771.

Kako, S., Isobe, A., Magome, S., Hinata, H., Seino, S., Kojima, A., 2011. Establishment of numerical beach-litter hindcast/forecast models: an application to Goto Islands. Jpn. Mar. Pollut. Bull. 62, 293-302.

Kako, S., Isobe, A., Kataoka, T., Hinata, H., 2014. A decadal prediction of the quantity of plastic marine debris littered on beaches of the East Asian marginal seas. Mar. Pollut. Bull. 81, 174-184.

Khatmullina, L., Isachenko, I., 2017. Settling velocity of microplastic particles of regular shapes. Mar. Pollut. Bull. 114, 871-880.

Koelmans, A.A., Besseling, E., Shim, W.J., 2015. Nanoplastics in the aquatic environment. Critical review. In: Marine anthropogenic Litter. Springer International Publishing, pp. 325-340.

Kooi, M., Reisser, J., Slat, B., Ferrari, F.F., Schmid, M.S., Cunsolo, S., Brambini, R. Noble, K., Sirks, L., Linders, T.E.W., Schoeneich-Argent, R.I., Koelmans, A.A., 2016. The effect of particle properties on the depth profile of buoyant plastics in the ocean. Sci. Rep. 6, 33882

Kowalski, N., Reichardt, A.M., Waniek, J.J., 2016. Sinking rates of microplastics and potential implications of their alteration by physical, biological, and chemica factors. Mar. Pollut. Bull. 109, 310-319.

Krelling, A.P., Souza, M.M., Williams, A.T., Turra, A., 2017. Transboundary movement of marine litter in an estuarine gradient: evaluating sources and sinks using hydrodynamic modelling and ground truthing estimates. Mar. Pollut. Bull. 119, 48-63.

Kubota, M., 1994. A mechanism for the accumulation of floating marine debris north of Hawaii. J. Phys, Oceanogr. 24, 1059-1064.

Kukulka, T., Proskurowski, G., Morét-Ferguson, S., Meyer, D.W., Law, K.L., 2012. The effect of wind mixing on the vertical distribution of buoyant plastic debris Geophys. Res. Lett. 39, L07601.

Kukulka, T., Law, K.L., Proskurowski, G., 2016. Evidence for the influence of surface heat fluxes on turbulent mixing of microplastic marine debris. J. Phys. Oceanogr. 46, 809-815.

Lattin, G.L., Moore, C.J., Zellers, A.F., Moore, S.L., Weisberg, S.B., 2004. A comparison of neustonic plastic and zooplankton at different depths near the southern California shore. Mar. Pollut. Bull. 49, 291-294.

Law, K.L. Morét-Ferguson, S., Maximenko, N.A. Proskurowski, G., Peacock, E.E. Hafner, J., Reddy, C.M., 2010. Plastic accumulation in the North Atlantic subtropical gyre. Science 329, 1185-1188.

Law, K.L., Thompson, R.C., 2014. Microplastics in the seas. Science 345, 144-145.

Law, K.L., Morét -Ferguson, S.E., Goodwin, D.S., Zettler, E.R., DeForce, E., Kukulka, T. Proskurowski, G., 2014. Distribution of surface plastic debris in the Eastern Pacific Ocean from an 11-year data set. Environ. Sci. Technol. 48, 4732-4738.

Lee, J., Hong, S., Song, Y.K., Hong, S.H., Jang, Y.C., Jang, M., Heo, N.W., Han, G.M. Lee, M.J., Kang, D., Shim, W.J., 2013. Relationships among the abundances of plastic debris in different size classes on beaches in South Korea. Mar. Pollut. Bull. 77, 349-354.

Lebreton, L.M., Greer, S.D., Borrero, J.C., 2012. Numerical modelling of floating debris in the world's oceans. Mar. Pollut. Bull. 64, 653-661.

Lechner, A., Keckeis, H., Lamesberger-Loisl, F., Zens, B., Krusch, R., Tritthart, M. Glas, M., Schludermann, E., 2014. The Danube so colourful: a potpourii of plastic litter outnumbers fish larvae in Europe's second largest river. Environ. Pollut. $188,177-181$.

Li, W.C., Tse, H.F., Fok, L., 2016. Plastic waste in the marine environment: a review of sources, occurrence and effects. Sci. Total Environ, 566, 333-349.

Liebezeit, G., Dubaish, F., 2012. Microplastics in beaches of the East frisian islands spiekeroog and katchelotplate. Bull. Environ. Contam. Toxicol. 89, 213-217.

Lima, A.R.A., Barletta, M., Costa, M.F., 2015. Seasonal distribution and interaction between plankton and microplastics in a tropical estuary. Estuar. Coast. Shelf Sci. 165, 213-225.

Liubartseva, S., Coppini, G., Lecci, R., Creti, S., 2016. Regional approach to modeling the transport of floating plastic debris in the Adriatic Sea. Mar. Pollut. Bull. 103 115-127.

Long, M., Moriceau, B., Gallinari, M., Lambert, C., Huvet, A., Raffray, J., Soudant, P. 2015. Interactions between microplastics and phytoplankton aggregates: impact on their respective fates. Mar. Chem. 175, 39-46.

Lusher, A.L., Tirelli, V., O'Connor, I., Officer, R., 2015. Microplastics in Arctic polar waters: the first reported values of particles in surface and sub-surface samples. Sci. Rep. 5, 14947.

Mansui, J., Molcard, A., Ourmieres, Y., 2015. Modelling the transport and accumulation of floating marine debris in the Mediterranean basin. Mar. Pollut. Bull. 91, $249-257$.

Martinez, E., Maamaatuaiahutapu, K., Taillandier, V., 2009. Floating marine debris surface drift: convergence and accumulation toward the South Pacific subtropical gyre. Mar. Pollut. Bull. 58, 1347-1355.

Mathalon, A., Hill, P., 2014. Microplastic fibers in the intertidal ecosystem surrounding halifax harbor, nova scotia. Mar. Pollut. Bull. 81, 69-79.

Maximenko, N., Hafner, J., Niiler, P., 2012. Pathways of marine debris derived from trajectories of Lagrangian drifters. Mar. Pollut. Bull. 65, 51-62.

McDermid, K.J., McMullen, T.L., 2004. Quantitative analysis of small-plastic debris on beaches in the Hawaiian archipelago. Mar. Pollut. Bull. 48, 790-794.

Moore, C.J., Moore, S.L., Weisberg, S.B., Lattin, G.L., Zellers, A.F., 2002. A comparison of neustonic plastic and zooplankton abundance in southern California's coastal waters. Mar. Pollut. Bull. 44, 1035-1038.

Moore, C.J., Lattin, G.L., Zellers, A.F., 2011. Quantity and type of plastic debris flowing from two urban rivers to coastal waters and beaches of Southern California. J. Integr. Coast. Zone Manag. 11, 65-73.

Moreira, F.T., Balthazar-Silva, D., Barbosa, L., Turra, A., 2016. Revealing accumulation zones of plastic pellets in sandy beaches. Environ. Pollut. 218, 313-321.

Morét -Ferguson, S., Law, K.L., Proskurowski, G., Murphy, E.K., Peacock, E.E., Reddy, C.M., 2010. The size, mass, and composition of plastic debris in the western North Atlantic Ocean. Mar. Pollut. Bull. 60, 1873-1878.

Muthukumar, T., Aravinthan, A., Lakshmi, K., Venkatesan, R., Vedaprakash, L., Doble, M., 2011. Fouling and stability of polymers and composites in marine environment. Int. Biodeterior. Biodegrad. 65, 276-284.

National Oceanic and Atmospheric Administration (NOAA) Marine Debris Program, 2016. Report on Modeling Oceanic Transport of Floating Marine Debris. Silver Spring, MD, p. 21.

Neumann, D., Callies, U., Matthies, M., 2014. Marine litter ensemble transport simulations in the southern North Sea. Mar. Pollut. Bull. 86, 219-228.

Ng, K.L., Obbard, J.P., 2006. Prevalence of microplastics in Singapore's coastal marine environment. Mar. Pollut. Bull. 52, 761-767.

Nor, N.H.M., Obbard, J.P., 2014. Microplastics in Singapore's coastal mangrove ecosystems. Mar. Pollut. Bull. 79, 278-283.

Pedrotti, M.L., Petit, S., Elineau, A., Bruzaud, S., Crebassa, J.C., Dumontet, B., Martí, E., Gorsky, G., Cózar, A., 2016. Changes in the floating plastic pollution of the Mediterranean Sea in relation to the distance to land. PloS one 11, e0161581.

PlasticsEurope, 2016. Plastics - the facts 2016. http://www.plasticseurope.org/ documents/document/20161014113313-plastics the facts 2016 final version. pdf.

Potemra, J.T., 2012. Numerical modeling with application to tracking marine debris. Mar. Pollut. Bull. 65, 42-50.

Raffel, M., Willert, C.E., Wereley, S., Kompenhans, J., 2013. Particle Image Velocimetry: a Practical Guide. Springer.

Reisser, J., Slat, B., Noble, K., du Plessis, K., Epp, M., Proietti, M., de Sonneville, J., Becker, T., Pattiaratchi, C., 2015. The vertical distribution of buoyant plastics at sea: an observational study in the North Atlantic Gyre. Biogeosci 12, 1249.

Ryan, P.G., 2015. Does size and buoyancy affect the long-distance transport of floating debris? Environ. Res. Lett. 10, 084019.

Sadri, S.S., Thompson, R.C., 2014. On the quantity and composition of floating plastic debris entering and leaving the Tamar Estuary, Southwest England. Mar. Pollut. Bull. 81, 55-60.

Sherman, P., Van Sebille, E., 2016. Modeling marine surface microplastic transport to assess optimal removal locations. Environ. Res. Lett. 11, 014006.

Shimanaga, M., Yanagi, K., 2016. The Ryukyu Trench may function as a "depocenter" for anthropogenic marine litter. J. Oceanogr. 72, 895-903.

Stolte, A., Forster, S., Gerdts, G., Schubert, H., 2015. Microplastic concentrations in beach sediments along the German Baltic coast. Mar. Pollut. Bull. 99, 216-229.

Sutton, R. Mason, S.A., Stanek, S.K., Willis-Norton, E., Wren, I.F., Box, C., 2016 Microplastic contamination in the san francisco Bay, California, USA. Mar. Pollut. Bull. 109, 230-235.

ter Halle, A., Ladirat, L., Gendre, X., Goudouneche, D., Pusineri, C., Routaboul, C., Tenailleau, C., Duployer, B., Perez, E., 2016. Understanding the fragmentation pattern of marine plastic debris. Environ. Sci. Technol. 50, 5668-5675.

Thiel, M., Gutow, L., 2005. The ecology of rafting in the marine environment. I. The floating substrata. Oceanogr. Mar. Biol. 42, 181-264.

Thiel, M., Hinojosa, I.A., Miranda, L., Pantoja, J.F., Rivadeneira, M.M., Vásquez, N., 2013. Anthropogenic marine debris in the coastal environment: a multi-year comparison between coastal waters and local shores. Mar. Pollut. Bull. 71, 307-316.

Thompson, R.C., Olsen, Y., Mitchell, R.P., Davis, A., Rowland, S.J., John, A.W., McGonigle, D., Russell, A.E., 2004. Lost at sea: where is all the plastic? Science 304, 838-838.

Thompson, R.C., 2015. Microplastics in the marine environment: sources, consequences and solutions. In: Marine anthropogenic Litter. Springer International Publishing, pp. 185-200.

Thornton, L., Jackson, N.L., 1998. Spatial and temporal variations in debris accumulation and composition on an estuarine shoreline, Cliffwood Beach, New Jersey, USA. Mar. Pollut. Bull. 36, 705-711.

Turra, A., Manzano, A.B., Dias, R.J.S., Mahiques, M.M., Barbosa, L., Balthazar-Silva, D. Moreira, F.T., 2014. Three-dimensional distribution of plastic pellets in sandy beaches: shifting paradigms. Sci. Rep. 4, 4435.

van Cauwenberghe, L., Vanreusel, A., Mees, J., Janssen, C.R., 2013. Microplastic pollution in deep-sea sediments. Environ. Pollut. 182, 495-499.

van Cauwenberghe, L., Devriese, L., Galgani, F., Robbens, J., Janssen, C.R., 2015. Microplastics in sediments: a review of techniques, occurrence and effects. Mar. Environ. Res. 111, 5-17.

van Sebille, E., England, M., Froyland, G., 2012. Origin, dynamics and evolution of ocean garbage patches from observed surface drifters. Environ. Res. Lett. 7, 1-6.

Veerasingam, S., Mugilarasan, M., Venkatachalapathy, R., Vethamony, P., 2016. Influence of 2015 flood on the distribution and occurrence of microplastic pellets along the Chennai coast, India. Mar. Pollut. Bull. 109, 196-204.

Vermeiren, P., Muñoz, C.C., Ikejima, K., 2016. Sources and sinks of plastic debris in 
estuaries: a conceptual model integrating biological, physical and chemical distribution mechanisms. Mar. Pollut. Bull. 113, 7-16.

Vianello, A., Boldrin, A., Guerriero, P., Moschino, V., Rella, R., Sturaro, A., Da Ros, L. 2013. Microplastic particles in sediments of Lagoon of Venice, Italy: first observations on occurrence, spatial patterns and identification. Estuar. Coast. Shelf Sci. 130, 54-61.

Waller, C.L., Griffiths, H.J., Waluda, C.M., Thorpe, S.E., Loaiza, I., Moreno, B., Pacherres, C.O., Hughes, K.A., 2017. Microplastics in the Antarctic marine system: an emerging area of research. Sci. Total Environ. 598, 220-227.

Wang, J., Tan, Z., Peng, J., Qiu, Q., Li, M., 2016. The behaviors of microplastics in the marine environment. Mar. Environ. Res. 113, 7-17.

Weinstein, J.E., Crocker, B.K., Gray, A.D., 2016. From macroplastic to microplastic: degradation of high-density polyethylene, polypropylene, and polystyrene in a salt marsh habitat. Environ. Toxicol. Chem. 35, 1632-1640.

Welden, N.A., Lusher, A.L., 2017. Impacts of changing ocean circulation on the distribution of marine microplastic litter. Integr. Enviro. Assess. Manage 13, 483-487.

Wolanski, E., Elliott, M., 2015. Estuarine Ecohydrology: an Introduction. Elsevier.

Woodall, L.C., Sanchez-Vidal, A., Canals, M., Paterson, G.L., Coppock, R., Sleight, V., Calafat, A., Rogers, A.D., Narayanaswamy, B.E., Thompson, R.C., 2014. The deep sea is a major sink for microplastic debris. R. Soc. Open Sci. 1, 140317.

Wright, S.L., Thompson, R.C., Galloway, T.S., 2013. The physical impacts of microplastics on marine organisms: a review. Environ. Pollut. 178, 483-492.

Yamashita, R., Tanimura, A., 2007. Floating plastic in the Kuroshio current area western north pacific ocean. Mar. Pollut. Bull. 54, 485-488.

Yonkos, L.T., Friedel, E.A., Perez-Reyes, A.C., Ghosal, S., Arthur, C.D., 2014. Microplastics in four estuarine rivers in the Chesapeake Bay, USA. Environ. Sci. Technol. 48, 14195-14202.

Yoon, J.H., Kawano, S., Igawa, S., 2010. Modeling of marine litter drift and beaching in the Japan Sea. Mar. Pollut. Bull. 60, 448-463.

Yu, X., Peng, J., Wang, J., Wang, K., Bao, S., 2016. Occurrence of microplastics in the beach sand of the Chinese inner sea: the Bohai Sea. Environ. Pollut. 214, $722-730$.

Zhao, S., Zhu, L., Li, D., 2015. Microplastic in three urban estuaries, China. Environ. Pollut. 206, 597-604.

Zhou, P., Huang, C., Fang, H., Cai, W., Dongmei, L., Xiaomin, L., Hansheng, Y., 2011. The abundance, composition and sources of marine debris in coastal seawaters or beaches around the northern South China Sea (China). Mar. Pollut. Bull. 62, 1998-2007. 